REVISTA DE DERECHO UNED, NÚM. 15, 2014

\title{
EL SUELO RURAL O NO URBANIZABLE COMO BIEN INTEGRANTE DEL PATRIMONIO MUNICIPAL DEL SUELO: ESPECIAL REFERENCIA A LOS NÚCLEOS RURALES
}

\author{
RURAL OR NON-DEVELOPABLE LAND AS A COMPONENT \\ OF THE MUNICIPAL LAND PATRIMONY: SPECIAL REFERENCE \\ TO RURAL TOWNSHIPS
}

\section{EsTEFANÍA PÉREZ LÓPEZ}

Funcionaria de Administración Local con habilitación de carácter nacional, subescala Secretaría, categoría Superior (Secretaria General del Ayuntamiento de Tineo -Asturias-). Doctorando del Departamento de Derecho Administrativo, Facultad de Derecho, Universidad Nacional de Educación a Distancia (UNED)

Resumen: Este estudio trata de analizar cuál ha sido la evolución del suelo rural o no urbanizable en España en relación a su pertenencia preceptiva al Patrimonio Municipal del Suelo y qué razones han llevado a que el citado tipo de suelo fuera considerado en el origen de la institución, representado por la Ley del Suelo de 1956, como un medio valioso para lograr la consecución de los fines propios de los Patrimonios Públicos del Suelo y haya dejado de serlo por el legislador actual. Lo expuesto aumenta su importancia si se tiene en cuenta la existencia de núcleos rurales situados en suelo no urbanizable donde efectivamente existen asentamientos de población dotados de servicios y donde es perfectamente posible ejecutar los fines propios de la institución.

Abstract: This study attempts to analyze the evolution of rural or non-developable land in Spain with regard to its mandatory pertenence to the Municipal Land Patrimony (equivalent to the British Commu- 
nity Land). It also inquires into the reasons why today, in contrast with the prevalent view when the Municipal Land Patrimony was initially established by the Land Act of 1956, lawmakers have stopped considering the aforementioned land types a valuable mean to achieve the proper objectives of the institution. The importance of this study increases if we take into account the existence of rural townships which, though located on non-developable land, effectively contain population settlements to whom services are provided and where it is perfectly possible to execute the proper goals of the institution.

Palabras clave: Suelo, público, rural, institución, desnaturalización.

Key words: Land, public, rural, institution, denaturalization.

Recepción original: 23/06/2014

Aceptación original: 25/07/2014

Sumario: I. Introducción. II. Evolución de la legislación estatal en materia de clasificación del suelo. Especial referencia al suelo rural. III. El suelo rural como bien integrante del patrimonio municipal del suelo en la legislación estatal básica desde 1956 y en la legislación autonómica actual. IV. El núcleo rural como bien integrante del patrimonio municipal del suelo. IV.1. Definición urbanística del núcleo rural. IV.2. El núcleo rural como bien integrante del patrimonio municipal del suelo. Problemas específicos en la zona septentrional española. V. Conclusiones.

\section{INTRODUCCIÓN}

La consideración del suelo rústico o rural como parte integrante del PMS ha sufrido variaciones en función del tiempo y del lugar. En el origen de la institución, entendida por tal la Ley del Suelo de 1956, el suelo rústico sí formaba parte del PMS. El Art. 73 se refería a la "adquisición de terrenos» sin concretar a qué clase de suelos se refería lo que abría claramente la posibilidad a la inclusión en el PMS de aquel tipo de suelo. Actualmente, vigente el TR 2008, resulta que éste no hace exigible la incorporación obligatoria al PMS de ningún tipo de terrenos, sea cual sea su clasificación urbanística, difiriendo esta posibilidad al legislador autonómico. Puede adelantarse que la mayor parte de las CCAA excluyen el ahora denominado suelo rural de su inclusión preceptiva en el PMS. Lo que trata de analizar este trabajo es por qué el suelo rural se consideraba en 1956 necesario para aco- 
ger los fines del PMS y por qué actualmente no se considera así, analizando cuáles han sido las circunstancias que han llevado a esta modificación. Lo expuesto aumenta su importancia si se tiene en cuenta la existencia de núcleos rurales situados en suelo no urbanizable o rural donde efectivamente existen asentamientos de población dotados de servicios y donde, como se explicará, es perfectamente posible ejecutar fines propios del PMS. No puede desconocerse la importancia que tiene determinar el papel que el suelo no urbanizable puede jugar dentro de los PMS. Siempre que no se trate de suelos que merezcan una especial protección y deban por tanto ser preservados del desarrollo urbano, el suelo no urbanizable puede constituir una interesante reserva de terrenos para futuros desarrollos de la ciudad y su adquisición a largo plazo por las Administraciones Públicas para su incorporación a los PMS puede considerarse como una opción perfectamente posible en aras a la consecución de los fines genéricos que le son propios a la institución.

\section{EVOLUCIÓN DE LA LEGISLACIÓN ESTATAL EN MATERIA DE CLASIFICACIÓN DEL SUELO. ESPECIAL REFERENCIA AL SUELO RURAL}

Con carácter previo al estudio del tema resulta conveniente hacer una breve exposición acerca de cuáles han sido desde 1956 los criterios de clasificación del suelo en España. Señalar a efectos formales que todos los epígrafes del presente apartado usan la denominación «suelo rural» para ser lo más fieles posibles con la nomenclatura del vigente TR 2008, a pesar de que este tipo de suelo ha recibido según el tiempo y el lugar nombres como no urbanizable, no urbanizado, rural o rústico. Actualmente se habla de clasificación del suelo para referirse a las grandes categorías urbanísticas de éste mientras que se usa el término calificación para señalar las distintas categorizaciones de cada una de las clases. Sin embargo, la Ley del Suelo de 1956 se refería a calificación del suelo para definir lo que hoy sería una clasificación. Así, en su Art. 63 fijaba los criterios que debería tener un suelo para considerarse urbano. El Art. 64 creó la categoría de «suelo de reserva urbana» definiéndolo como aquel suelo comprendido en un plan general de ordenación para ser urbanizado y no calificable como suelo urbano. Finalmente el Art. 65 definió por residualidad el suelo rústico señalando como tales aquellos terrenos que no fueren incluibles en las dos categorías precedentes. La Ley del Suelo de 1975 introduce la denominación "suelo urbanizable» y clasifica el suelo en sus Art. 73, 74 y 75 como urbano, urbanizable y no urbanizable vol- 
viendo a otorgar un carácter residual al suelo no urbanizable al señalar que el mismo vendrá constituido por el suelo que el plan no incluya como urbano o urbanizable pero añadiendo además que también formarán parte del suelo no urbanizable «los espacios que el plan determine para otorgarle una especial protección, (...), en razón de su excepcional valor agrícola, forestal o ganadero, de las posibilidades de explotación de sus recursos naturales, de sus valores paisajísticos, históricos, culturales o para la defensa de la fauna, flora o el equilibrio ecológico». En los mismos términos se expresan los Art. 76 a 80 del Texto Refundido de 1976. El Art. 9 del TR 92 que señalan que «el planeamiento clasificará el territorio en todas o algunas de las siguientes clases: Suelo urbano, urbanizable, o en su caso apto para urbanizar y no urbanizable, o clases equivalentes a los efectos de la Ley, reguladas por la legislación autonómica». El Art. 12 del mismo texto legal definió el suelo no urbanizable como aquellos «terrenos que el planeamiento general no incluya en ninguna de las clases de suelo anteriores -urbano y urbanizable- y, en particular, los espacios que dicho planeamiento determine para otorgarles una especial protección, en razón de su excepcional valor agrícola, forestal o ganadero, de las posibilidades de explotación de sus recursos naturales, de sus valores paisajísticos, históricos o culturales, o para la defensa de la fauna, la flora o el equilibrio ecológico». La Ley 6/1998, de 13 de abril, de régimen de suelo y valoraciones, establecía en su Art. 7 que el suelo se clasifica en urbano, urbanizable y no urbanizable o clases equivalentes reguladas por la legislación urbanística. Con respecto al suelo no urbanizable señalaba en su Art. 9 que la consideración de suelo no urbanizable se otorgaba a los suelos con especiales valores paisajísticos, agrícolas, forestales... o aquellos que el planeamiento urbanístico considerase dignos de protección. La Ley 6/1998, no realiza exactamente una categorización del suelo no urbanizable (respetando la competencia de las CCAA), sin embargo de su contenido sí se pueden extraer las dos categorías clásicas de suelo no urbanizable. En primer lugar, el Art. 9 recoge la categoría de suelo no urbanizable de especial protección cuya clasificación viene impuesta al planificador:

1. Por los planes de ordenación territorial o la legislación sectorial, en razón de sus valores paisajísticos, históricos, arqueológicos, científicos, ambientales o culturales.

2. Por el planeamiento sectorial debido a los riesgos naturales que prevea.

3. En función de su sujeción a limitaciones o servidumbres para la protección del dominio público. 
Puede decirse que existe una especie de subcategoría en este suelo que podría denominarse como preservado. Se trata de aquel suelo que por decisión del planeador sea necesario preservar del desarrollo urbano por sus valores agrícola, forestal o ganadero o las riquezas naturales que pudiera tener. Este suelo se caracteriza por su naturaleza discrecional, frente al antes citado que es de carácter reglado. En segundo lugar, el Art. 9.2 de la Ley 6/1998, recoge el suelo no urbanizable común que engloba el suelo no urbanizable en el que no concurren valores que justifiquen su preservación o protección y que resultan inadecuados para el desarrollo urbano bien por una gestión racional de los recursos naturales o bien en respuesta a criterios objetivos de tipo urbanístico o territorial si así no recoge la normativa urbanística aplicable.

La Ley de Suelo 8/2007, de 28 de mayo, señala en su Art. 12.1 (Art. 12 TR 2008) que todo suelo se encuentra, a los efectos de esta Ley, en una de las situaciones básicas del suelo rural o de suelo urbanizado. Según la nueva Ley «está en la situación de suelo rural:

1. En todo caso, el suelo preservado por la ordenación territorial y urbanística de su transformación mediante la urbanización que deberá incluir, como mínimo, los terrenos excluidos de dicha transformación por la legislación de protección o policía del domino público, de la naturaleza o del patrimonio cultural, los que deban quedar sujetos a tal protección conforme a la ordenación territorial y urbanística por los valores en ellos concurrentes, incluso los ecológicos, agrícolas, ganaderos, forestales y paisajísticos, así como aquellos con riesgos naturales o tecnológicos, incluidos los de inundación o de otros accidentes graves y cuantos otros prevea la legislación de ordenación territorial o urbanística.

2. El suelo para el que los instrumentos de ordenación territorial y urbanística prevean o permitan su paso a la situación de suelo urbanizado, hasta que termine la correspondiente actuación de urbanización, y cualquier otro que no reúna los requisitos a que se refiere el apartado siguiente».

El citado apartado se refiere a aquellos terrenos que se encuentran en la situación de suelo urbanizado definiéndolo como aquel «integrado de forma legal y efectiva en la red de dotaciones y servicios propios de los núcleos de población. Se entenderá que así ocurre cuando las parcelas, estén o no edificadas, cuenten con las dotaciones y los servicios requeridos por la legislación urbanística o puedan llegar a contar con ellos sin otras obras que las de conexión de la parcelas a las instalaciones ya en funcionamiento. Al establecer las dotaciones y 
servicios a que se refiere el párrafo anterior, la legislación urbanística podrá considerar las peculiaridades de los núcleos tradicionales legalmente asentados en el medio rural». Nótese que la Ley de Suelo de 2007 describe las situaciones básicas del suelo «a efectos de esta Ley» lo cual habrá de hacerlas compatibles con el sistema de clasificación del suelo previsto por los legisladores autonómicos.

\section{EL SUELO RURAL COMO BIEN INTEGRANTE DEL PATRIMONIO MUNICIPAL DEL SUELO EN LA LEGISLACIÓN ESTATAL BÁSICA DESDE 1956 Y EN LA LEGISLACIÓN AUTONÓMICA ACTUAL}

La Ley del Suelo de 1956 incluía entre los bienes que deberían formar parte de la institución todos los bienes patrimoniales municipales ${ }^{1}$ sin diferenciar con respecto a su clasificación urbanística. Como se señaló en la introducción la Ley hablaba de «adquisición de terrenos» para su incorporación al PMS sin distinción de ningún tipo. El Art. 72 de la Ley del Suelo de 1956 afirmaba que el PMS se adscribirá a la gestión urbanística para la inmediata preparación y enajenación de solares edificables y reserva de terrenos de futura utilización. Puesto que la necesidad es de futuro es lógico extraer la conclusión de que puede adquirirse tanto terreno urbano como rústico, de hecho la adquisición de suelo rústico encaja perfectamente con el concepto de previsión para una futura extensión de la ciudad. Ninguna duda se planteó por tanto en 1956 sobre el hecho de que el suelo rústico sí formaba parte del PMS. La regulación realizada por la Ley del Suelo de 1975 y posterior Texto Refundido de 1976 en esta materia fue muy similar a la que realizó la Ley del Suelo de 1956 por lo que el suelo rústico quedó claramente incluido entre los bienes integrantes del PMS ${ }^{2}$. En cuanto a la Ley de 1990 y posterior TR 92 resulta que ésta por primera vez excluyó el suelo rústico de formar parte con carácter obligatorio del PMS permitiendo no obstante que se integrara en éste si así lo decidía la Administración municipal competente. Así el Art. 277 se expresaba diciendo que forman parte del PMS «los bienes patrimoniales que resulten clasificados por el planeamiento urbanístico como suelo urbano o urbani-

${ }^{1}$ Art. 73.3 de la Ley del Suelo de 1956 «cuando resultaren incluidos en el plan bienes de propios, quedarán afectados al patrimonio municipal del suelo».

${ }^{2}$ El Art. 90.3 del Texto Refundido de la Ley del Suelo de 1976 señala que «cuando resulten incluidos en el plan bienes de propios quedarán afectados al patrimonio municipal del suelo». Se expresa en los mismos términos que la Ley del Suelo de 1956 sin hacer distinción sobre la clasificación urbanística de los bienes de propios por lo que se entiende que todos los bienes de propios municipales, incluido el suelo rústico, forma parte integrante del patrimonio municipal del suelo. 
zable programado y, en todo caso los obtenidos como consecuencia de cesiones, ya sea en terrenos o en metálico expropiaciones urbanísticas de cualquier clase y ejercicio del derecho de tanteo y retracto. Igualmente se incorporarán al Patrimonio Municipal del Suelo los terrenos clasificados como suelo urbanizable no programado o no urbanizable que se adquieran con dicha finalidad». Es decir, es perfectamente posible que el suelo rústico forme parte del PMS pero no es necesario que así sea en todos los casos quedando a discreción de la Administración Local esta decisión. La Ley 6/1998, salvo la alusión hecha en su Art. 40.3 a posibles reversiones de suelo, no se pronuncia sobre los patrimonios municipales del suelo, por lo que no podemos extraer de ella conclusiones sobre la inclusión o no del suelo rural en el PMS. El Art. 38 del TRLS 2008 (anterior Ley 2007) señala que integrarán el patrimonio público del suelo «los bienes, recursos y derechos que adquiera la Administración en virtud del deber a que se refiere la letra b) del apartado 1 del Art. 16, sin perjuicio de los demás que determine la legislación sobre ordenación territorial y urbanística». El Art. 16.1.b) se refiere a las cesiones que correspondan a la Administración urbanística actuante en concepto de plusvalías correspondientes a la comunidad. Puesto que la obligatoriedad para el particular de efectuar estas cesiones no se produce en suelo rústico podemos concluir que el suelo rural no es de obligatoria inclusión entre los bienes integrantes del PMS. No obstante debe matizarse que la Ley 8/2013, de 26 de junio, de rehabilitación, renovación y regeneración urbanas, a través de su Disposición Adicional Duodécima Diez, modifica el Art. 16.5 del TR 2008 para señalar que «las actuaciones sobre núcleos tradicionales legalmente asentados en el medio rural, comportarán los deberes legales establecidos en los números anteriores, de acuerdo con las características que a éstos atribuya su propia legislación». Por tanto, en los términos de las legislaciones autonómicas (y no con la aplicación directa del TR 2008) podrán exigirse cesiones en núcleos de población asentados en suelo rústico. No obstante, el Art. 38.1 del TR 2008 no ha sido modificado y sigue señalando como único integrante necesario del PMS las cesiones contempladas en el Art. 16.1.b) y no las contempladas en el Art. 16.2 del TR 2008.

Las regulaciones autonómicas en la materia pueden agruparse en torno a dos grandes filosofías: las que incluyen el suelo rural como bien preceptivamente integrante en el PMS y las que no lo hacen. El Art. 72 de la Ley 7/2002, de 17 de diciembre, de ordenación urbanística de Andalucía, señala que integran los PPS los bienes patrimoniales incorporados por decisión de la Administración", es decir, no define una inclusión automática de bienes patrimoniales en función de su clasificación 
urbanística por lo que el suelo rústico (al igual que el urbanizado) formará parte del PMS según lo decida la voluntad municipal. Para el Art. 112 de la Ley 3/2009, de 17 de junio, de urbanismo de Aragón, el PMS viene integrado por los terrenos de naturaleza patrimonial que resulten clasificados como urbano o urbanizable, excluyendo por tanto el suelo rústico de su pertenencia necesaria al PMS. En los mismos términos que el anterior se expresa el Art. 216.1.a) del TROTU asturiano. La norma canaria conformada por el Decreto Legislativo 1/2000, de 8 de mayo, utilizando un modelo similar al previsto en Andalucía, sí permite la incorporación por decisión municipal del suelo rústico al PMS al señalar en su Art. 74.3 que éste estará formado por los bienes patrimoniales que así se disponga sin hacer distinción sobre su clasificación urbanística. La Ley 2/2001 de Cantabria se alinea con aquellas CA que solo consideran PMS a los suelos clasificados como urbano o urbanizable (Art. 230.1.a). El Art. 77 del Decreto Legislativo 1/2010 de Castilla La Mancha otorga el carácter de PMS a todos aquellos terrenos a los que una disposición legal o reglamentaria incluyendo el planeamiento urbanístico asigne tal destino o vincule a fines propios de la institución. No existe por tanto una exclusión a priori de suelo por su clasificación urbanística sino que la inclusión o no viene determinada por una asignación concreta de finalidades. Según el Art. 124.1.b) de la Ley 5/1999, de 8 de abril, de urbanismo de Castilla y León, integran el PMS los terrenos de naturaleza patrimonial que sean clasificados como suelo urbano no consolidado o suelo urbanizable de uso residencial, por tanto tampoco el suelo rústico se incluye preceptivamente entre los bienes integrantes del PMS. El Decreto Legislativo 1/2010, de 3 de agosto, por el que se aprueba el Texto Refundido de la Ley de Urbanismo de Cataluña, redactado ya con posterioridad a la Ley de Suelo de 2007, señala que el PMS viene constituido de forma obligatoria únicamente por los terrenos correspondientes a los porcentajes de cesión obligatoria y gratuita a la Administración (Art. 163), cesiones de terrenos que, hasta la reforma del Art. 16.2 TR 2008 por la Ley 26/2013, solo existían en el suelo urbano y urbanizable. Para el Art. 89. e) de la Ley 15/2001, de 14 de diciembre, de suelo y ordenación del territorio de Extremadura, el suelo rústico no forma parte necesaria del PMS ya que solo lo integran los terrenos clasificados como urbano o urbanizable. En la misma línea se sitúa Galicia, cuando el Art. 176 de la Ley 9/2002, de 30 de diciembre, de ordenación urbanística y protección del medio natural, vuelve a referirse como bienes incluidos en el PMS al suelo urbano y al urbanizable olvidando de nuevo el suelo rústico. El Art. 179 de la Ley 5/2006, de 2 de mayo, de ordenación del territorio y urbanismo de La Rioja, tampoco incluye el suelo rural entre los componentes preceptivos del PMS al señalar que «integrarán el patrimonio municipal del suelo los 
bienes inmuebles de titularidad municipal que teniendo ya naturaleza patrimonial, resulten clasificados por el planeamiento urbanístico como suelo urbano o urbanizable». La Ley 9/2001, de 17 de julio, del suelo, de la Comunidad de Madrid, en su Art. 174 no define los bienes patrimoniales que integran el PMS en función de su clasificación urbanística sino que lo hace en función de la voluntad de la Administración. El Art. 197 del Decreto Legislativo 1/2005, de 10 de junio, por el que se aprueba el Texto Refundido de la Ley del Suelo de la Región de Murcia, dispone que «integran los patrimonios públicos del suelo los bienes patrimoniales que se adscriban expresamente a los mismos» con independencia de su clasificación urbanística por lo que será de nuevo la voluntad municipal la que decida la inclusión del suelo rústico o no sin que ésta resulta en sí misma preceptiva. La Ley Foral de Navarra $35 / 2002$, de 20 de diciembre, de ordenación del territorio y urbanismo, en su Art. 224 faculta a los Ayuntamientos para incorporar a su PMS los bienes patrimoniales clasificados como suelo urbano o urbanizable por lo que no contempla como obligatoria la incorporación al PMS de suelos con distinta clasificación urbanística a la señalada. Para la Ley 2/2006, de 30 de junio, de suelo y urbanismo del País Vasco, constituyen preceptivamente el PMS únicamente los bienes patrimoniales situados en terrenos clasificados como suelo urbano o urbanizable. Finalmente, el Art. 260 de la Ley 16/2005, de 30 de diciembre, de la Generalitat, urbanística de Valencia, dispone que el PMS se integra por los bienes patrimoniales a los que el planeamiento territorial y urbanístico asigne expresamente tal destino así como aquellos que legal o reglamentariamente se adscriban al patrimonio público del suelo por lo que la decisión al respecto vuelve a ser de la Administración actuante.

De las distintas regulaciones autonómicas vigentes puede concluirse que las de Aragón, Asturias, Cantabria, Castilla y León, Cataluña, Galicia, La Rioja, Navarra y País Vasco se refieren siempre a los bienes patrimoniales de la Administración integrantes del PMS como aquellos a los que el planeamiento otorgue la clasificación de suelo urbano o urbanizable excluyendo por tanto el suelo rústico de su necesaria inclusión en el PMS. No obstante, las regulaciones de Aragón, Cantabria, Castilla y León, Galicia y País Vasco abren la puerta a posibles inclusiones de suelo rural al permitir a la Administración actuante incorporar al voluntariamente al PMS cualquier tipo de bienes. Este carácter voluntario es el que está presente en las legislaciones autonómicas de Andalucía, Canarias, Castilla La Mancha, Extremadura, Madrid, Murcia y Valencia que otorgan a la Administración municipal la facultad de decidir qué bienes patrimoniales integran 
su PMS con independencia de la clasificación urbanística de éstos lo que supone que el suelo rústico no forma ex lege parte del PMS.

A la vista de lo expuesto resulta clara la involución que el suelo rural ha tenido como elemento configurador del PMS. La Ley del Suelo de 1956, en cuanto primigenia regulación de los patrimonios públicos del suelo, incluyó el suelo rústico entre los bienes integrantes de la institución considerando posible materializar sobre este suelo los fines propios de la figura. Esta concepción se mantuvo hasta la Ley de 1990 donde el PMS se centró en los suelos urbanos y urbanizables dejando el suelo rural como una mera categoría residual que podía ser o no objeto de incorporación en función de la voluntad de la Administración. Algunas legislaciones autonómicas, las señaladas, siguen esta línea de forma que el suelo rústico no forma parte con carácter obligatorio del PMS. De lo expuesto se deduce que el suelo rural no se considera actualmente un valor para el PMS. Es sensato, indiscutible y comúnmente aceptado que determinados suelos con un elevado nivel de protección por sus valores paisajísticos, ambientales, culturales, arqueológicos... o bien por su función protectora de costas, infraestructuras, cuencas... queden fuera de todo proceso urbanizador promovido por el ser humano. Sin embargo existen espacios de suelo rústico «común» que perfectamente podrían formar parte del PMS y constituir verdaderas bolsas de terrenos adquiridos por la Administración para futuras actuaciones urbanísticas. Después de todo, los fines genéricos del PMS no son otros que regular el mercado de terrenos, obtener reservas de suelo para actuaciones de iniciativa pública y facilitar la ejecución de la ordenación territorial y urbanística (Art. 34 TR 2008) por lo que resulta sensato plantearse la adquisición de suelo rural a efectos de materializar actuaciones futuras. Si a lo expuesto se añade el estudio de la figura del núcleo rural, como a continuación se hará, resulta que es posible implantar en suelo rústico los destinos otorgados a los bienes integrantes de la institución y así proceder a la promoción en núcleos rurales de viviendas de protección pública u otros fines de interés social.

\section{EL NÚCLEO RURAL COMO BIEN INTEGRANTE DEL PATRIMONIO MUNICIPAL DEL SUELO}

\section{IV.1. Definición urbanística del Núcleo Rural}

Definir el núcleo rural no es en realidad tarea sencilla sin embargo no es tan difícil señalar cuál sea su definición como concretar su adscripción a una clase u otra de suelo. Con carácter general el núcleo 
rural ha sido tratado como parte del suelo rural o rústico, aunque con matices que luego se verán. Sin embargo, este suelo tiene en realidad vocación de uso residencial por lo que reúne perfectas condiciones para integrarse en el PMS y permitir la consecución sobre él de los fines que son propios a la institución. El concepto de «núcleo rural» no aparece definido como tal en las leyes estatales en materia de urbanismo promulgadas desde 1956. Partiendo de que se trata de un concepto jurídico indeterminado (así lo avaló la STS de 10 de diciembre de 1986) se han tratado de dar algunas definiciones del núcleo rural. Así, BLANQUER PRATS ${ }^{3}$, ha definido el núcleo de población como «el germen de la estructura de un sistema social ordenado que, a partir de cierto grado de desarrollo, requiere el tratamiento propio de una sociedad de carácter urbano». Tal vez la clave esté en la expresión «cierto grado de desarrollo» y en función del grado de desarrollo alcanzado por el grupo de población debamos decidir la clasificación urbanística del suelo sobre el que se asientan los núcleos de población, pasando a definir estos bien como rurales o bien como urbanos. Tanto en el Texto Refundido de 1976 como en el Texto Refundido de 1992 las referencias al núcleo de población aparecen como negativas en orden a preservar la posibilidad de su creación en suelo no urbanizable al considerarlo un fenómeno urbano e incompatible con esa clase de suelo. Los siguientes preceptos, sin ánimo exhaustivo, hacen referencia a la figura del núcleo de población. El Art. 85 del TR 76 se refiere a la posibilidad de autorizar edificación aislada en suelo no urbanizable siempre que no exista riesgo de que se forme núcleo de población ni tenga características urbanas. En desarrollo de este precepto los Art. 34 d), 36 b), 90 c), 91 y 93 del Reglamento de Planeamiento Urbanístico de 1976 señalan que el planeamiento general deberá recoger el concepto de núcleo de población a efectos del Art. 85 del TR 76 en los suelos urbanizables no programados y no urbanizables. El Reglamento de Gestión Urbanística en sus Art. 44 y 45 regula el procedimiento para la autorización de edificaciones aisladas en suelo urbanizable no programado y suelo no urbanizable. La Ley del Suelo de 1998 no hace referencias a la figura del núcleo rural. La nueva Ley de Suelo de 2007 hace por primera vez un guiño a la figura del núcleo rural dando a entender implícitamente que este es un suelo «urbanizado». Así, en el Art. 12, al definir el suelo urbano, señala que "al establecer las dotaciones y servicios a que se refiere el párrafo anterior, la legislación urbanística podrá considerar las peculiaridades de los núcleos tradicionales legalmente asentados en el medio rural».

${ }^{3}$ BLANQUER PRATS, M. B «Las bases fundamentales del núcleo de población». Revista de Derecho Urbanístico, n. ${ }^{\circ}$ 72, marzo-abril 1981. Pags. 13 y siguientes.

(C) UNED. Revista de Derecho UNED, núm. 15, 2014 
Pero donde cobra verdadera carta de naturaleza el núcleo rural es en las legislaciones autonómicas, especialmente aquellas de la zona norte española donde el núcleo rural es forma común de asentamiento de la población.

\section{IV.2. El núcleo rural como bien integrante del patrimonio municipal del suelo. Problemas específicos en la zona septentrional española}

Como se ha señalado el núcleo rural es en realidad un núcleo de población, un asentamiento humano que cuenta con servicios y donde es perfectamente posible desarrollar la vida diaria. Tradicionalmente se ha compuesto de viviendas unifamiliares vinculadas a la explotación agrícola o ganadera de los terrenos rústicos sobre los que éstas se asentaban. Con el tiempo, estos núcleos de población eminentemente vinculados al sector primario, han ido evolucionando y se han convertido, en muchos casos, en verdaderos asentamientos residenciales, no vinculados a explotación económica alguna. Considerando que la mayor parte de los núcleos rurales se sitúan sobre suelo clasificado como no urbanizable y que gran número de CCAA excluyen el suelo no urbanizable de los bienes integrantes del PMS, se puede extraer como primera conclusión, que luego será matizada, que los suelos municipales patrimoniales situados en núcleos rurales no forman preceptivamente parte del PMS. Tratándose de un suelo sobre el que existen asentamientos efectivos de población se plantean cuestiones tales como por qué no es posible realizar sobre ellos viviendas protegidas o implantar usos de interés social. En resumen, por qué el suelo público situado en núcleos rurales no forma parte del PMS. A estas cuestiones tratará de darse respuesta a través del estudio de la figura del núcleo rural en las CCAA de Galicia, Asturias, Cantabria y País Vasco puesto que es en la cornisa norte peninsular donde el núcleo rural está realmente implantado como espacio de residencia de la población y donde, por tanto, es más fácil materializar objetivos propios del PMS.

La legislación asturiana es paradigma de lo que se quiere explicar. El Art. 122 del Real Decreto 1/2004, de 22 de abril, por el que se aprueba el texto refundido de las disposiciones legales vigentes en materia de ordenación del territorio y urbanismo de Asturias (TROTUA) señala como categorías de suelo no urbanizable las siguientes: suelo no urbanizable de especial protección, suelo no urbanizable de interés, suelo no urbanizable de costas, suelo no urbanizable de infraestructu- 
ras y núcleo rural. Esta categorización es en todo caso abierta, puesto que se contempla la posibilidad de que la normativa sectorial pueda establecer otras subdivisiones en razón del origen de la necesidad de protección y la intensidad de ésta. A modo de resumen podemos decir que la Ley define el suelo no urbanizable de especial protección como aquel integrado por aquellos espacios cuyos excepcionales valores de cualquier género les hagan merecedores de un alto grado de protección. El suelo no urbanizable de Interés ${ }^{4}$ es el compuesto por aquellos terrenos que, sin estar incluidos en ninguna otra de las categorías que recoge el Art. 122 TROTUA, deben quedar preservados del desarrollo urbanístico y sometidos a un régimen específico de protección por disponerlo así el planeamiento en atención a sus valores paisajísticos, históricos, arqueológicos, científicos, ambientales o culturales, por la existencia de riesgos naturales debidamente acreditados, singularidades agrícolas, forestales o ganaderas, o para la preservación del peculiar sistema de doblamiento del territorio asturiano, así como en función de sujeción a limitaciones o servidumbres para la protección del dominio público. También se integraran en esta categoría de suelo los terrenos situados alrededor de los núcleos rurales cuya preservación del proceso urbanizador sea conveniente para el mantenimiento del propio núcleo y sus valores. Define el precepto el suelo no urbanizable de costas como ese suelo respecto al cual deben establecerse las medidas de protección que requieren las especialidades de las franjas costeras. Los terrenos que resulten afectados por la localización de infraestructuras básicas o de transportes conformarán el suelo no urbanizable de infraestructuras. Por último el Art. 122 define el Núcleo Rural como la categoría de suelo no urbanizable objeto de ocupación residencial.

Interesa detenerse en la figura del Núcleo Rural y en su vinculación con los bienes integrantes del PMS. El Art. 216 del TROTUA considera bienes que en todo caso integran el PMS aquellos bienes patrimoniales que tengan la clasificación de suelo urbano o urbanizable. A sensu contrario, excluye el suelo clasificado como no urbanizable. Puesto que, a tenor del Art. 122 del TROTUA el núcleo rural es parte integrante del suelo no urbanizable, resulta que los suelos municipales patrimoniales situados en núcleo rural no son parte del PMS y como conclusión lógica no es preceptivo materializar sobre ellos actuacio-

${ }^{4}$ La función que desempeñaba el suprimido por la Ley asturiana suelo no urbanizable genérico pasa a ser encomendada al suelo no urbanizable de interés, por cuanto el TROTUA lo configura como una categoría genérica y residual, al definirlo como «los terrenos que, sin estar intuidos en ninguna de las categorías de este artículo, deban quedar preservados del desarrollo urbanístico. Art. 122.1. b) TROTUA.

(C) UNED. Revista de Derecho UNED, núm. 15, 2014 
nes propias de la institución. Con las categorías de suelo no urbanizable contempladas por el TROTUA (excepto el núcleo rural) parece una decisión lógica excluir del PMS este tipo de suelo puesto que esos suelos están destinados a otros destinos (protección de valores paisajísticos, agrícolas, históricos, etc. ) que nada tienen que ver con los fines propios del PMS. El argumento de la Ley podría ser que los fines propios del PMS deben llevarse a cabo en un entorno urbano, es decir, sobre suelos urbanos o urbanizables (urbanizados como dice la nueva Ley de Suelo de 2007). Sin embargo, resulta que el núcleo rural en Asturias en un suelo con usos similares a los previstos en aquellos. El Art. 136 del TROTUA define el núcleo rural como aquellos «asentamientos consolidados de población en suelo no urbanizable que el planeamiento municipal configure con tal carácter, en función de las circunstancias edificatorias, socioeconómicas y de cualquier otra índole que manifiesten la imbricación racional del asentamiento en el medio físico donde se sitúa. Se incluirán en esta categoría los asentamientos de población que, pese a contar eventualmente con servicios de acceso rodado, abastecimiento de agua, saneamiento y suministro de energía eléctrica para sus necesidades propias como tales asentamientos rurales, no estén integrados en una malla urbana en los términos establecidos en el Art. 113 apartado a) de este Texto Refundido. En orden a la obtención del suministro de los servicios públicos de electricidad, telefonía y otros semejantes, los núcleos rurales se equiparan a los suelos urbanos y demás asentamientos de población de análoga naturaleza o denominación. El hecho de que un asentamiento clasificado por el planteamiento urbanístico general como núcleo rural, o algún terreno dentro del mismo, disponga o pase a disponer en un momento determinado de acceso rodado, abastecimiento de agua, evacuación de aguas, suministro de energía eléctrica, acceso a servicios de telefonía y telecomunicaciones y semejantes para la satisfacción de las necesidades de su población, no implicará su conversión en suelo urbano ni obligará al Ayuntamiento a modificar el Plan General de Ordenación en tal sentido». De esta definición puede extraerse fácilmente la conclusión de que los valores, usos o actividades del núcleo rural son similares a los que pueden desarrollarse en un espacio más urbano y se alejan de los parámetros propios de un suelo no urbanizable (rural tras la Ley de Suelo de 2007). Se trata de una ficción jurídica para recoger una especial forma de asentamiento de la población en Asturias, y en el norte de España, que no tiene parangón en el resto del territorio nacional. Sin cuestionar la oportunidad de la figura desde el punto urbanístico, sí debe cuestionarse, por el contrario, por qué este suelo no es considerado necesario para desarrollar en él las finalidades propias del PMS. El núcleo rural dispone 
de todos, o casi todos, los servicios con los que cuenta el suelo urbano, es, en todo caso, un suelo perfectamente habitable. El Núcleo Rural es un tipo de suelo apto para su ocupación residencial, es más, se define precisamente por la existencia de asentamientos de población, que son en realidad la esencia misma de su existencia, su razón de ser y de existir en la legislación autonómica asturiana. La cuestión que surge entonces es por qué los terrenos que lo conforman quedan excluidos del PMS, por qué no se contempla la posibilidad de construir sobre ellos viviendas de protección pública o de implantar fines de interés social. Se trata de un suelo que cuenta con todos los servicios básicos y que, además, como veremos a continuación, permite desarrollar diversos usos compatibles con el residencial que harían perfectamente posible que en ese entorno se desarrollaran viviendas sometidas a algún régimen de protección en un espacio totalmente habitable. No hay motivo para que este suelo no sea utilizado como PMS. Todos los fines propios de este patrimonio separado recogidos en el Art. 217 del TROTUA se pueden desarrollar, en una u otra medida, en los núcleos rurales, especialmente el señalado en la letra b) referido a la construcción de vivienda protegida.

Según CARRERO DE ROA ${ }^{5}$ se han construido un total de 1.257 viviendas en suelo clasificado como no urbanizable con la calificación núcleo rural en los concejos del área central de Asturias entre 2000 y 2004. Esto supone un porcentaje del 3,56 \% con respecto al número total de viviendas construidas en todo el territorio autonómico. Se observa por tanto que la construcción de una vivienda en núcleo rural es una opción válidamente escogida por los ciudadanos y que, por tanto no habría obstáculos sociales a que los núcleos acogieran, obviamente con respeto a las limitaciones que le son propias, la construcción de viviendas de protección e incluso cualesquiera otros usos de interés social al servicio de la población que en ellos habita. Es más, los núcleos rurales son especialmente atractivos para fijar población por las ventajas de gestión urbanística que encierran.

BORISSOVA BONEVA ${ }^{6}$ hace un excelente repaso a los motivos en que se basa este atractivo entre los que destaca el deterioro de la calidad de vida en la ciudad señalando que las ciudades se densifican cada vez más haciendo desaparecer en entorno natural y produciendo

${ }^{5}$ CARRERO DE ROA, M. «La complejidad de la ordenación del territorio del área centra de Asturias» en El medio rural y la difusión urbana. FERNÁNDEZ GARCÍA, A. y ALONSO IBÁÑEZ, M. R. (Coord.). Oviedo, Ediciones KRK, 2007.

${ }^{6}$ BORISSOVA BONEVA, M. «El traslado de la vivienda al medio rural: urbanizaciones y viviendas aisladas» en El medio rural y la difusión urbana. FERNÁNDEZ GARCÍA, A. y ALONSO IBÁÑEZ, M. R. (Coord.). Oviedo, Ediciones KRK, 2007. 
un exceso de contaminación a lo que se añade que la típica estructura urbana repercute negativamente en la iluminación y ventilación de las viviendas. Estos problemas, se reducen sensiblemente, o posiblemente, dejan de existir en los núcleos rurales. El segundo factor que señala con mayor relevancia es el precio de la vivienda. La relación calidad-precio ofertada en una ciudad es mucho peor que la ofertada en un núcleo rural. Habla además del «monofuncionalismo del territorio». Se detecta «un proceso de traslado fuera de las ciudades de los equipamientos, servicios, zonas industriales, áreas de ocio, etc. Todo ello hace imprescindible en la vida diaria de la persona disponer de algún medio de transporte público o privado. Esta dependencia en todo caso del transporte resta ventajas al centro urbano creando demanda en posibles núcleos rurales bien comunicados con la ciudad y los parques de ocio, industriales o tecnológicos. El tiempo de traslado entre el centro de la ciudad y un barrio periférico de ésta puede ser superior al tiempo de traslado entre el centro y un núcleo rural próximo. Agotadas las posibilidades de relleno de las ciudades, a éstas sólo les queda crecer a través de barrios periféricos. La calidad de oferta de este emplazamiento puede ser muy inferior a la calidad que puede ofrecer un emplazamiento rural cercano. Por otro lado la importante mejora de la red viaria hace que las distancias no se midan en kilómetros sino en tiempo y en comodidad, lo que deja muy bien situados a diversos núcleos rurales. Por último la proximidad de zonas de calidad paisajística y medioambiental alta, playas, parques naturales, espacios protegidos, etc., la menor contaminación y la tranquilidad y la seguridad de la vida cotidiana hacen que vivir en el medio rural sea más atractivo que vivir en el medio urbano».

Así las cosas resulta que el núcleo rural es un espacio óptimo para la implantación de viviendas, incluidas aquellas sometidas a algún régimen de protección pública cuya construcción es destino propio del PMS. Debe tenerse claro que el núcleo rural no es solo un tradicional asentamiento de viviendas sino también un nuevo asentamiento de viviendas. Recoge una demanda existente en la sociedad. Si ello es así, carece de sentido obviar que parte de estas viviendas podrían ser también de protección pública dando cumplimiento así a los fines propios del PMS, lo que llevaría la necesidad de una modificación del Art. 216 del TROTUA para incluir entre los bienes integrantes del PMS además de los bienes patrimoniales clasificados por el planeamiento urbanístico como urbanos o urbanizables también aquellos clasificados por el planeamiento como no urbanizables siempre que tengan la califica- 
ción de núcleo rural. Incluso, en adaptación al TRLS $2008^{7}$ que considera el núcleo rural como suelo urbanizado, podría otorgarse a aquellos directamente esta clasificación lo que supondría su automática inclusión en el PMS. Sin embargo, el legislador asturiano no ha tomado hasta el momento ninguna de las dos opciones descritas e insiste en mantener los núcleos rurales como parte del suelo no urbanizable y por tanto de no inclusión preceptiva en el PMS. Esta situación lleva a que algunos Ayuntamientos asturianos ${ }^{8}$ hayan enajenado suelo de su propiedad sito en núcleos rurales a constructoras privadas para la construcción, en la mayor parte de los casos, de vivienda unifamiliar de lujo. El importe de las enajenaciones habrá de destinarse por los Ayuntamientos a cualesquiera fines, siempre dentro de los parámetros del Art. 5 del Texto Refundido de la Ley reguladora de Haciendas Locales. Ni el suelo ni el importe de su enajenación están vinculados a los destinos propios del PMS regulados en el Art. 217 del TROTUA. Esta desvinculación no es en modo alguno reprochable a la actuación municipal que se ha limitado a la venta un bien patrimonial. El reproche, en su caso, debe dirigirse al legislador que no detecta la necesidad de que los suelos municipales con la calificación de núcleo rural se integren en los PMS.

Esta visión del núcleo rural en Asturias es exportable al resto de Comunidades Autónomas del territorio Norte español. La normativa urbanística cántabra viene representada actualmente por la Ley $2 / 2001$, de 25 de junio, de ordenación territorial y régimen urbanístico de Cantabria, con las importantes modificaciones (especialmente en materia de suelo rústico que ahora nos interesa) introducidas por la Ley 2/2009, de 3 de julio, de modificación de la anterior y por la Ley 3/2012, de 21 de junio, también de modificación de la primera. En lo que se refiere al concepto de núcleos rurales debe partirse de la Ley 2/2001 cuya exposición de motivos considera ya el hecho de

${ }^{7}$ El Art. 12.4 del Real Decreto Legislativo 2/2008, de 20 de junio, por el que se aprueba el texto refundido de la ley de suelo, dispone, tras la modificación operada por el apartado siete de la disposición final duodécima de la Ley 8/2013, de 26 de junio, de rehabilitación, regeneración y renovación urbanas, que «también se encuentra en la situación de suelo urbanizado, el incluido en los núcleos rurales tradicionales legalmente asentados en el medio rural, siempre que la legislación de ordenación territorial y urbanística les atribuya la condición de suelo urbano o asimilada y cuando, de conformidad con ella, cuenten con las dotaciones, infraestructuras y servicios requeridos al efecto».

${ }^{8}$ El Boletín Oficial del Principado de Asturias de fecha 31 de marzo de 2011 publica anuncio de licitación del Ayuntamiento de Gijón para la enajenación de parcelas patrimoniales municipales situadas en núcleo rural sin adscribir las mismas a fines propios del PMS. Sirva como ejemplo de las muchas actuaciones acontecidas en Asturias en este sentido. 
la preexistencia en Cantabria de unos asentamientos tradicionales como la pedanía, la aldea o el barrio, que deben seguir existiendo. Continúa señalando que «la ley no contempla una indiscriminada proliferación de este tipo de asentamientos que, sin control, podrían conducir a consecuencias negativas difíciles de reparar». De ahí que solo permita este tipo de edificaciones en suelo rústico de protección ordinaria en los supuestos y con las limitaciones que establezca el planeamiento territorial o, en su caso, las previsiones más limitativas del planeamiento municipal». Parte por tanto del reconocimiento de esta situación geográfica especial relativa a los núcleos rurales. Con la derogada Ley urbanística de Cantabria 9/1994, reguladora de los usos del suelo en el medio rural, el núcleo rural era una calificación del suelo no urbanizable. La Disposición Transitoria Segunda de la Ley 2/2001 modificó este aspecto y determinó que los núcleos rurales así calificados por el planeamiento pasan a tener la consideración de suelo urbano, aplicándoseles el régimen de los pequeños municipios, es decir, el correspondiente a los Ayuntamientos que cuentan con una población inferior a 1.000 habitantes y un número de viviendas no superior a 400. El Art. 95.1.d) de la Ley urbanística de Cantabria, dispone que tienen la consideración de suelo urbano «los terrenos que, no contando con los requisitos legalmente establecidos para ser clasificados como suelos urbanos, sirven de soporte a un asentamiento de población singularizado que merezca una consideración específica en función de sus características morfológicas, tipología tradicional de las edificaciones, vinculación con la explotación racional de los recursos naturales o circunstancias de otra índole que manifiesten la imbricación racional del núcleo con el medio físico donde se sitúa». El núcleo rural o tradicional forma parte por tanto del suelo urbano. Según MENÉNDEZ ALONSO ${ }^{9}$ "con la equiparación del núcleo rural tradicional, concebido originariamente como una categoría de suelo rústico, al suelo urbano, se propició una desmesurada presión urbanística en este tipo de asentamientos que en su mayor parte carecían de los servicios necesarios y obligatorios para tener la consideración de suelo urbano. La Ley 7/2007, de medidas fiscales y de contenido financiero, modificó la Ley 2/2001, introduciendo un nuevo artículo 100 bis titulado "régimen del suelo urbano de núcleo tradicional" que expresamente prohíbe todas aquellas actividades, construcciones y usos que desvirtúen las características que hayan fundamentado la inclusión de terrenos dentro de la categoría de núcleo tradicional». La regulación establecida en 2007 autoriza también las construcciones

\footnotetext{
9 «MENÉNDEZ ALONSO, J. M. La nueva regulación del suelo rústico en Cantabria: especial referencia a las viviendas unifamiliares. Práctica Urbanística. Número 87, noviembre de 2009.»
} 
vivideras en suelo rústico de protección ordinaria. La reforma operada en torno al suelo rústico por la Ley 2/2009, mantiene la configuración del núcleo tradicional como suelo urbano y autoriza tanto en el suelo rústico de protección ordinaria como en el de especial protección, las obras de reestructuración, renovación y reforma de edificaciones preexistentes (sometido todo ello a determinadas condiciones). La Ley de 2007 además de seguir posibilitando la construcción de viviendas unifamiliares en suelo rústico de protección ordinaria, faculta la nueva construcción de este tipo de viviendas, así como actividades artesanales, de ocio y turismo rural en los terrenos próximos a los suelos urbanos y a lo núcleos tradicionales reflejados en el planeamiento, siempre previa aprobación de un plan especial de suelo rústico.

La reforma operada por la Ley 3/2012, de 21 de junio, tiene como finalidad, según su exposición de motivos, ampliar la relación de usos y actividades que pueden llevarse a cabo en suelo rústico con la finalidad de favorecer la dinamización social y económica de este tipo de suelo. Así, modifica el Art. 94.2 de la Ley urbanística cántabra para señalar que el suelo urbano seguirá el régimen del urbano consolidado y el suelo restante el del rústico de especial protección. No se modifica el Art. 95.1.d) por lo que los núcleos tradicionales siguen incardinados dentro del suelo urbano. Recapitulando, en Cantabria el suelo se clasifica en urbano, urbanizable y rústico. Dentro del suelo urbano existe un tipo de calificación denominada suelo urbano de núcleo tradicional y dentro del suelo rústico podemos encontrarnos con suelo rústico de especial protección y suelo rústico de protección ordinaria. En cuanto a la configuración de los bienes integrantes del PMS en Cantabria, según dispone el Art. 230.1.a) de la Ley 2/2001, integrarán el PMS los bienes de titularidad municipal que resulten clasificados como suelo urbano o urbanizable. De ello se deduce que, a diferencia de lo que ocurre en Asturias, los suelos municipales ubicados en zonas típicas de núcleo rural o tradicional están incluidos en el PMS puesto que están clasificados como suelo urbano de núcleo tradicional. Su carácter de suelo urbano los incorpora automáticamente al PMS. Esto parece sensato si se tiene en cuenta que, según los razonamientos antes expuestos para el caso asturiano, este tipo de suelos son perfectamente válidos para acoger vivienda protegida $\mathrm{u}$ otros fines de interés social. En Cantabria la reflexión sería diferente: si la reforma operada en la Ley cántabra en 2009 permite la construcción de viviendas unifamiliares y actividades de ocio y turismo rural en suelo no urbanizable de protección ordinaria, ¿por qué no se incluye este tipo de suelo también dentro de los bienes integrantes 
del PMS? En este caso el razonamiento iría dirigido a la defensa de la inclusión en el PMS no solo del núcleo rural, ya incluido por ser un suelo urbano, sino del suelo no urbanizable de protección ordinaria en la medida en la que es posible la concreción de asentamientos urbanos sobre el mismo.

En el caso de Galicia, otra de las Comunidades septentrionales en las que son típicos los asentamientos de población en forma de núcleos rurales o tradicionales, la Ley 9/2002, de 30 de diciembre, de ordenación urbanística y protección del medio rural de Galicia, realiza la clasificación del suelo en sus Artículos 10 y siguientes, de forma que clasifica en suelo en cuatro tipos: urbano, de núcleo rural, urbanizable y rústico. El Art. 13 señala que constituyen el suelo de núcleo rural los terrenos que sirven de soporte a un asentamiento de población singularizado en función de sus características morfológicas, tipología tradicional de las edificaciones, vinculación con la explotación racional de los recursos naturales o de circunstancias de otra índole que manifiesten la imbricación racional del núcleo con el medio físico donde se sitúa. A la vista de esta descripción queda claro que se trata del mismo fenómeno geográfico que en el caso de Asturias y Cantabria, sin embargo, a diferencia de estas Comunidades la opción legislativa gallega es distinta en orden a clasificar este tipo de suelos. Mientras que en Asturias en núcleo rural es una calificación dentro del suelo clasificado como no urbanizable y en Cantabria, por contra, el núcleo tradicional es una calificación dentro del suelo urbano, Galicia ha optado por configurar los núcleos rurales como una cuarta clase de suelo con autonomía propia al mismo nivel que el suelo urbano, el urbanizable y el no urbanizable. Para el suelo clasificado como núcleo rural establece (Art. 27) un uso característico residencial, permitiendo usos comerciales, productivos, turísticos y tradicionales ligados a la vida rural, así como pequeños talleres. Se permite la construcción de nuevas edificaciones y la forma de ejecución de las mismas conlleva la cesión gratuita de los terrenos necesarios para la apertura o regularización del viario y la ejecución a costa del promotor de la urbanización y la conexión con los servicios existentes en el núcleo. A la vista de lo expuesto y siguiendo la teoría manifestada hasta el momento resulta que el núcleo rural en Galicia también es suelo perfectamente apto para albergar en él los fines propios del PMS. Sin embargo, el Art. 176 de la Ley tampoco ha incluido entre los bienes integrantes de este patrimonio los suelos patrimoniales municipales clasificados como núcleo rural. A tal efecto, el apartado 2 del citado Art. 176 dispone que integrarán el PMS los bienes patrimoniales que resultasen clasificados por el planeamiento 
urbanístico como suelo urbano o urbanizable por lo que, a sensu contrario, resulta que el suelo municipal clasificado como núcleo rural no forma necesariamente parte del PMS.

La Comunidad Autónoma del País Vasco establece un cuarto modelo para la clasificación del núcleo rural. Si Asturias lo consideraba una calificación dentro del suelo no urbanizable, Cantabria una calificación dentro del suelo urbano y Galicia le otorgaba el rango de clasificación autónoma, el País Vasco establece un sistema mixto entre los dos primeros. La Ley 2/2006, de 30 de junio, de suelo y urbanismo, clasifica en su Art. 10 el suelo como urbano, urbanizable y no urbanizable. El núcleo rural se define en el Art. 29 como la agrupación de entre seis y veinticinco caseríos en torno a un espacio público que los aglutina y confiere su carácter. Preceptúa que la superficie de suelo ocupada por un núcleo rural podrá ser clasificada por el plan general como suelo urbano o como suelo no urbanizable de núcleo rural. En cuanto a la incorporación de terrenos patrimoniales municipales así clasificados al PMS, el Art. 113 señala que necesariamente integran el PMS los bienes patrimoniales municipales que el planeamiento general clasifique como suelo urbano o urbanizable. Es decir, quedarán automáticamente integrados en el PMS los suelos situados en núcleos rurales cuando éstos hayan sido clasificados por el planeamiento como suelo urbano y, por el contrario, no se incorporarán necesariamente los suelos situados en núcleos rurales cuando el planeamiento los haya clasificado como suelo no urbanizable.

Habida cuenta de lo expuesto resulta que los asentamientos de población denominados «núcleos rurales» suponen el mismo fenómeno geográfico en toda la zona norte española pese a lo cual han sufrido distintos tratamientos urbanísticos en función de la decisión de cada legislador autonómico lo que ha generado a su vez diferentes resultados en cuanto a la inclusión preceptiva o no en el PMS de los bienes municipales situados en tales suelos.

\section{Conclusiones}

El reconocimiento legal de la figura del PMS se contempla por primera vez en la Ley del Suelo de 1956. Esta norma no dudó en entender el suelo rústico como un valor para el PMS y así en su Art. 73.3 dispuso que todos los bienes de propios incluidos en el plan debían quedar afectados al PMS. Según el Art. 9 de la Ley los planes debían delimitar el perímetro urbano y señalar el suelo rústico por lo que, en puridad, ambos tipos de suelo se incluían dentro del plan y por tanto 
integraban el PMS. El concepto de «reserva de terrenos de futura utilización» usado por la Ley animaba a pensar que el suelo rústico encajaba con el concepto de previsión para una futura extensión de la ciudad. De esta concepción del suelo rústico como parte necesaria para el desarrollo de la institución del PMS se ha pasado a la concepción actual en la que el TR 2008, en su Art. 38, solo considera como parte necesariamente integrante del PMS las cesiones urbanísticas a que se refiere el Art. 16.1.b) del mismo cuerpo legal. Las cesiones urbanísticas están ligadas al desarrollo de suelos urbanos o urbanizables y no al desarrollo del suelo rural (no susceptible de desarrollo por definición) por lo que no habrá ningún suelo rústico que integre necesariamente el PMS. En todo caso se recuerda que la Ley 8/2013, de 26 de junio, de rehabilitación, renovación y regeneración urbanas, modificó el Art. 16.5 del TR 2008 haciendo exigibles sobre núcleos tradicionales legalmente asentados en el medio rural, en los términos de la legislación autonómica correspondiente, los deberes legales fijados en principio para suelos urbanos y urbanizables. Por ello las cesiones urbanísticas que se produjeran en los núcleos rurales como consecuencia de esta modificación podrían pasar a formar parte del PMS. Sin embargo el Art. 38 del TR 2008 no ha sido modificado en tal sentido y sigue insistiendo en que el PMS está formado por las cesiones previstas en el Art. 16.1.b) no incorporando las cesiones urbanísticas que pudieran producirse en virtud del modificado Art. 16.5 del TR 2008. La decisión de incluir suelo rústico en el PMS corresponde al legislador autonómico que, como hemos visto, no ha decidido su incorporación preceptiva sino únicamente su incorporación voluntaria en función de la decisión de la Administración actuante. Así las cosas resulta que el suelo rural común, un suelo apto para acoger futuros desarrollos urbanísticos, no formará en ningún caso parte del PMS a no ser que así lo decida el Ayuntamiento correspondiente.

El caso de los núcleos rurales se hace aún más complejo si tenemos en cuenta que se trata de verdaderos asentamientos de población, con servicios y posibilidades de desarrollos urbanísticos. En Asturias el núcleo rural se configura como una calificación del suelo no urbanizable y no integra el PMS, en Cantabria se considera una calificación del suelo urbano y por tanto sí forma parte del PMS, en Galicia aparece como una cuarta clasificación autónoma del suelo no constitutivo del PMS y finalmente en el País Vasco nos encontramos con un sistema mixto en el que el planeamiento puede clasificar el núcleo rural como suelo urbano o como suelo no urbanizable formando parte del PMS en todo caso cuando se encuentre en el primer supuesto y sólo cuando así lo decida la Administración en el segundo. 
Sin embargo, en todos los casos el NR se configura como un espacio habitable y por tanto susceptible de integrarse en el PMS para poder materializar sobre él los fines que le son propios a la institución. El carácter semi-urbano de estos núcleos se ve también apoyado por el Real Decreto Legislativo 1/2004, de 5 de marzo, por el que se aprueba el texto refundido de la Ley del Catastro Inmobiliario, cuyo Art. 7 señala, si bien únicamente a efectos catastrales, que el carácter urbano o rústico de un inmueble dependerá de la naturaleza de su suelo y entiende por suelo de naturaleza urbana el ocupado por núcleos o asentamientos de población aislados, en su caso, del núcleo principal, cualquiera que sea el hábitat en el que se localicen y con independencia del grado de concentración de las edificaciones.

A pesar de que las legislaciones autonómicas contemplan la posibilidad de que los Ayuntamientos incorporen a su PMS con carácter voluntario cualesquiera bienes y derechos entre los cuales pueden encontrarse los suelos patrimoniales municipales clasificados como suelo rural, lo cierto es que el legislador pierde una oportunidad importante de atribuir a tal incorporación el carácter de preceptiva. La no consideración del suelo rural como un valor para la integración de los PMS, especialmente en el caso de los núcleos rurales, es una carencia que debería reconsiderarse y que solo puede conceptuarse como una verdadera involución de la institución con su respecto al germen originario de su creación en la Ley del Suelo de 1956. Esta situación viene a poner de manifiesto, una vez más, la grave desnaturalización que está sufriendo en los últimos tiempos la institución del PMS.

\section{BIBLIOGRAFÍA}

BLANQUER PRATS, M. B «Las bases fundamentales del núcleo de población». Revista de Derecho Urbanístico, n. ${ }^{\circ}$ 72, marzo-abril 1981.

BORISSOVA BONEVA, M. «El traslado de la vivienda al medio rural: urbanizaciones y viviendas aisladas» en El medio rural y la difusión urbana. FERNÁNDEZ GARCÍA, A. y ALONSO IBÁÑEZ, M. R. (Coord.). Oviedo, Ediciones KRK, 2007.

CARRERO DE ROA, M. «La complejidad de la ordenación del territorio del área central de Asturias» en El medio rural y la difusión urbana. FERNÁNDEZ GARCÍA, A. y ALONSO IBÁÑEZ, M. R. (Coord.). Oviedo, Ediciones KRK, 2007. 
MENÉNDEZ ALONSO, J. M. «La nueva regulación del suelo rústico en Cantabria: especial referencia a las viviendas unifamiliares». Práctica Urbanística. Número 87, noviembre de 2009. 